\title{
Candidate proteomic biomarkers in systemic sclerosis discovered using mass-spectrometry: an update of a systematic review (2014-2020)
}

\author{
PAUL BĂLĂNESCU ${ }^{1,2,3 *}$, ANCA BĂLĂNESCU ${ }^{4 *}$, EUGENIA BĂLĂNESCU², CRISTIAN BĂICUȘȘ ${ }^{1,2,3}$ \\ ${ }^{1}$ University of Medicine and Pharmacy Carol Davila, Internal Medicine Chair, Bucharest, Romania \\ ${ }^{2}$ Clinical Immunology Laboratory CDPC, Colentina Clinical Hospital, Bucharest, Romania \\ ${ }^{3}$ Clinical Research Unit RECIF (Reseau d'Epidemiologie Clinique International Francophone), Bucharest, Romania \\ ${ }^{4}$ University of Medicine and Pharmacy Carol Davila, Pediatrics Chair, Bucharest, Romania \\ ${ }^{*}$ These two authors contributed equally to this work
}

\begin{abstract}
Background. Systemic sclerosis (Ssc) is an autoimmune disease characterized by graduate cutaneous and tissue fibrosis development and irreversible fibroproliferative vascular changes.

The aim of the current systematic review was to update the list of proteomic candidate biomarkers identified from Ssc samples with mass spectrometry techniques.

Methods. Medline and Scopus databases were searched on $1^{\text {st }}$ September 2020. Relevant articles were searched from March 2014 until September 2020. Two independent reviewers evaluated the retrieved articles.

Results. From a total of 97 articles, 9 articles were included in the final analysis summarizing 539 candidate proteomic biomarkers from various samples from Ssc patients (a larger number compared to the previous systematic review). Most biomarkers were identified from cutaneous biopsies. Only 5 articles included a validation step of the findings with only 13 biomarkers being validated.
\end{abstract}

Conclusions. Although many candidate biomarkers were additionally identified, independent validation studies are needed in order to evaluate the importance of these biomarkers for Ssc patients.

Key words: systemic sclerosis, biomarker, proteomic, mass spectrometry, validation.

\section{What is new? What is important?}

The current work presents an update for candidate proteomic biomarkers for Ssc patients identified using mass spectrometry techniques. 539 biomarkers were identified. Only a small number of biomarkers have been validated on independent cohorts and future confirmation studies are mandatory in order to evaluate their diagnostic/prognostic capacity.

\section{INTRODUCTION}

Systemic sclerosis $(\mathrm{Ssc})$ is an autoimmune disease characterized by graduate cutaneous and tissue fibrosis development and irreversible fibroproliferative vascular changes [1]. Scientific community is focusing its efforts in order to discover relevant biomarkers for diagnosis, prognosis and therapeutic response of such patients. However, this task is not easy as it is rather difficult to find a highly specific and sensitive biomarker or biomarker panel due to the great variability of the disease. Biomarkers have several characteristics that should be always taken into account: intra- or inter-individual variability, validity and most importantly they should be practical [2]. Therefore, validation studies of candidate biomarkers that test all these aspects are crucial. Proteomic biomarkers have the advantage to be easily quantified in routine clinical laboratory setting using immune-based reactions (ELISA) as they do not need expensive equipments, nor intensive personnel training [3]. Candidate proteomic biomarkers can be identified using mass spectrometry techniques. However, this is only the first step, as multiple confirmatory independent studies using antibody based assays are needed in order to confirm and validate the candidate proteomic biomarker in the clinical setting.

The aim of the current systematic review was to update the list of proteomic candidate biomarkers identified with mass spectrometry techniques from Ssc patient's samples. Previous list of candidate biomarkers was published in 2014 and comprised articles indexed in Medline from inception until 
February 2014 [4]. Such list could help the scientific community to identify relevant biomarkers that should be confirmed and validated on independent Ssc cohorts.

\section{MATERIAL AND METHODS}

A comprehensive research strategy (Table 1) was applied in two medical databases: Medline and Scopus on $1^{\text {st }}$ September 2020. Relevant articles were searched from March 2014 until September 2020. Only articles in English language were included in the analysis. Two independent reviewers (PB and $\mathrm{AB})$ evaluated the title and abstracts of retrieved articles and decided about inclusion/exclusion of articles. Where there were discrepancies between decision of inclusion/exclusion, the two reviewers discussed and reached consensus. Letters to editor, review articles, editorials and case reports were excluded. Also studies performed on animal models were excluded from the analysis. Only articles that analyzed various biological samples from Ssc patients using mass spectrometry techniques were included. Eligible articles were analyzed full text and data was extracted by the two independent reviewers in a database. The database contained the bibliographic reference of the article, mass spectrometry technique used for analysis, number of Ssc patients and controls, sample type, proteomic biomarkers that were identified, and also fold changes compared to controls (if given). In addition, if the article also comprised a validation cohort for the identified biomarkers, these details were also included in the analysis. In the end, quality of reported data from the studies was evaluated using criteria described previously by Mischak et al., 2010 [5]. They refer to justification of clinical question, assessing of subject description, sampling description, clear methodological description, presentation of statistical approach for the data analysis, validation of findings, limitation acknowledgments and also clearly statement of each author contribution.

\title{
Table 1
}

Research strategy for inclusion of relevant articles

\begin{abstract}
Medline search strategy
(((("scleroderma, systemic"[MeSH Terms] OR (((("scleroderma, systemic"[MeSH Terms] OR ("scleroderma"[All Fields] AND "systemic"[All Fields])) OR "systemic scleroderma"[All Fields]) OR ("systemic"[All Fields] AND "sclerosis"[All Fields])) OR "systemic sclerosis"[All Fields])) OR ("scleroderma, systemic"[MeSH Terms] OR "scleroderma, localized"[MeSH Terms])) OR (((((("scleroderma, systemic"[MeSH Terms] OR ("scleroderma"[All Fields] AND "systemic"[All Fields])) OR "systemic scleroderma"[All Fields]) OR "scleroderma"[All Fields]) OR "scleroderma, localized"[MeSH Terms]) OR ("scleroderma"[All Fields] AND "localized"[All Fields])) OR "localized scleroderma"[All Fields]) OR "sclerodermas"[All Fields])) AND (((("mass spectrometry"[MeSH Terms] OR ("mass"[All Fields] AND "spectrometry"[All Fields])) OR "mass spectrometry"[All Fields]) OR ("2D"[All Fields] AND (((("electrophoresed"[All Fields] OR "electrophoresing"[All Fields]) OR "electrophoresis"[MeSH Terms]) OR "electrophoresis"[All Fields]) OR "electrophorese"[All Fields]) OR "electrophoreses"[All Fields]))) OR ((("proteomics"[MeSH Terms] OR (((()(("proteom"[All Fields] OR "proteome"[MeSH Terms]) OR "proteome"[All Fields]) OR "proteomes"[All Fields]) OR "proteomical"[All Fields]) OR "proteomically"[All Fields]) OR "proteomics"[MeSH Terms]) OR "proteomics"[All Fields]) OR "proteomic"[All Fields])) OR "proteome"[MeSH Terms]) OR ((((()(("proteom"[All Fields] OR "proteome"[MeSH Terms]) OR "proteome"[All Fields]) OR "proteomes"[All Fields]) OR "proteomical"[All Fields]) OR "proteomically"[All Fields]) OR "proteomics"[MeSH Terms]) OR "proteomics"[All Fields]) OR "proteomic"[All Fields])))) AND 2014/01/01:2020/12/31[Date - Publication]) NOT ((("amyotrophic lateral sclerosis"[MeSH Terms] OR (("amyotrophic lateral sclerosis"[MeSH Terms] OR (("amyotrophic"[All Fields] AND "lateral"[All Fields]) AND "sclerosis"[All Fields])) OR "amyotrophic lateral sclerosis"[All Fields])) OR (("multiple sclerosis"[MeSH Terms] OR ("multiple"[All Fields] AND "sclerosis"[All Fields])) OR "multiple sclerosis"[All Fields])) OR "multiple sclerosis"[MeSH Terms])

Scopus search strategy

PUBYEAR > 2014 TITLE-ABS-KEY ( systemic AND sclerosis OR scleroderma) AND mass AND spectrometry OR 2d AND electrophoresis OR proteomics OR proteome NOT mice OR animal.
\end{abstract}

\section{RESULTS}

The search strategy retrieved 97 articles (70 indexed in Medline and 27 indexed in Scopus). After removal of 8 duplicates, a total number of 89 articles were included for the preliminary analysis. 21 articles were reviews articles and were excluded from the analysis. Also 4 editorials were excluded from the analysis. Two articles in Japanese and one article in Czech were also excluded. 61 articles had their abstract and titles analyzed and among these 13 were included for full text analysis. After full text analysis, two articles were excluded due to the fact that they did not present exploratory proteomic studies, and two articles used SOMASCAN method. Therefore in the end 9 articles had their information retrieved in the database (Figure 1) [6-14]. 


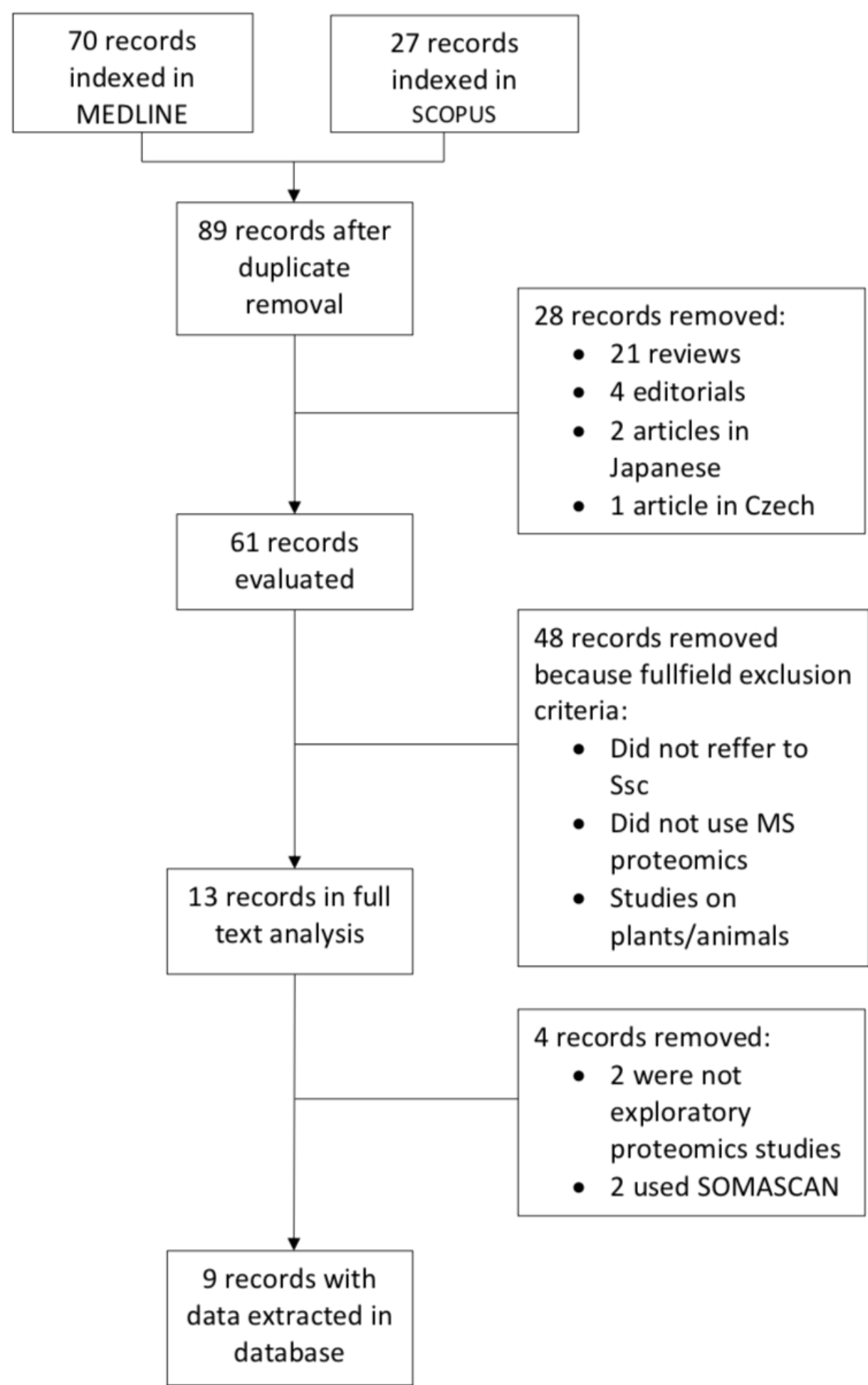

Figure 1. Flowchart of the systematic review.

\section{Patients and control groups}

In total, $162 \mathrm{Ssc}$ patients were recruited. In all studies, healthy controls were included. Most studies included healthy matched controls (for gender and age (8/9 studies) and one study clearly stated that healthy controls were not matched with Ssc patients [12]. Matching is very important because some biomarkers are known to have gender and age variation and differences can rise only from the fact that controls were not matched with Ssc cases. In one study [7], healthy controls were further divided into smoker and non-smokers (as biological sample analyzed in this particular study was 
BALF (bronchoalveolar lavage fluid), and thus smoking status is an important confounder due to the secondary inflammation caused by cigarette smoke).

\section{Biological samples}

Table 2 summarizes data extracted from the 9 articles included in the final analysis. As observed, most studies explored proteomics from biopsy of affected Ssc tissues (4/9 studies). 3 of these studies evaluated modifications of the proteome from skin biopsies, and one study evaluated pulmonary biopsies from patients with ILD in Ssc. Two studies evaluated modifications from plasma samples, while only one study included BALF. Two studies evaluated "in vitro" changes of the fibroblast proteome (cultured from patient skin and pulmonary samples). These studies were also included in the analysis due to the fact that they could pinpoint relevant "in vivo" biomarkers that are related with fibroblasts, the key cell in Ssc pathogenesis.

Table 2

Summarization of included articles (biological sample, sample size and proteomic technique)

\begin{tabular}{|c|c|c|c|}
\hline Reference & Biological sample & Sample size & Proteomic technique used \\
\hline Ryu et al., [6] & Plasma & 14 Ssc with ILD /10 healthy controls & LC-MS/MS \\
\hline Landi et al., [7] & $\begin{array}{l}\text { Bronchoalveolar lavage } \\
\text { fluid }\end{array}$ & $\begin{array}{l}7 \mathrm{Ssc} / 10 \text { healthy non-smoker } \\
\text { controls/8 healthy smoker controls }\end{array}$ & 2DE, MALDI-TOF/TOF \\
\hline Corralo et al., [8] & Skin biopsy & $5 \mathrm{lcSsc} / 5$ healthy controls & 2 DE,MALDI-TOF/TOF \\
\hline van Bon et al., [9] & Plasma & $\begin{array}{l}67 \mathrm{lcSsc} \text { and } 33 \mathrm{dcSSc} / 19 \text { healthy } \\
\text { controls }\end{array}$ & SELDI-TOF-MS \\
\hline Chairta et al., [10] & Skin biopsy & $\begin{array}{l}7 \text { Ssc patients } 2 \text { biopsies/each patient - } \\
\text { from affected and unaffected }\end{array}$ & LC-MS/MS \\
\hline Mullenbrock et al., [11] & $\begin{array}{l}\text { Pulmonary myofibroblast } \\
\text { cell culture supernatant }\end{array}$ & $\begin{array}{l}10 \text { pulmonary fibrosis } / 10 \text { Ssc patients } \\
/ 10 \text { healthy controls }\end{array}$ & LC-MS/MS \\
\hline Chaigne et al., [12] & $\begin{array}{l}\text { Cutaneous fibroblast cell } \\
\text { culture supernatant }\end{array}$ & $4 \mathrm{dSsc} / 3$ unmatched healthy controls & $\begin{array}{l}\text { 2DE-DIGE/MALDI-TOF } \\
\text { MS }\end{array}$ \\
\hline Dumi et al., [13] & Skin biopsy & 3 Ssc patients/3 healthy controls & 2DE, LC-MS/MS \\
\hline Schiller et al., [14] & Pulmonary biopsy & $\begin{array}{l}45 \text { endstage Ssc with ILD/ } 10 \text { healthy } \\
\text { controls }\end{array}$ & LC-MS/MS \\
\hline
\end{tabular}

ILD - interstitial lung disease, dSsc - diffuse systemic sclerosis, 1Ssc - localized systemic sclerosis, 2DE - two dimension electrophoresis, 2DE-DIGE - two-dimension electrophoresis fluorescence difference gel electrophoresis, MALDI - Matrix-assisted laser desorption/ionization, LC-MS/MS - Liquid chromatography-mass spectrometry, TOF - Time of flight, SELDI-TOF-MS surface enhanced laser desorption/ionization-time of flight mass spectrometry.

\section{Proteomic technique}

Most studies used either 2 dimension electrophoresis or 2D DIGE as first step for protein separation. Spots and fractions were separated and compared using statistical measures with control group, thus identifying relevant candidate spots. For identification of spots, several mass spectrometry techniques were used (MALD-TOF, SELDI-TOF or LC-MS/MS). Most frequent used mass spectrometry technique was LC-MS/MS (5/9 studies).

\section{Candidate proteomic biomarkers}

Table 3 summarizes proteomic biomarkers found. In total, 539 candidate proteomic biomarkers from various samples of Ssc patients were identified being up- or downregulated compared to control group. Among these, 247 were downregulated, and 286 were upregulated. 2 proteins were either upregulated or downregulated (alpha 1 antitrypsin and apoptosis regulator BAX). For the rest of four proteins, the expression was unknown [8]. Most biomarkers were identified from biopsy samples (320 from cutaneous samples, and 44 from pulmonary samples). 86 biomarkers were identified from fibroblast culture supernatant. 60 candidate biomarkers were found from plasma, and finally only 29 biomarkers were identified from BALF.

\section{Quality assessment of reported data}

All articles included in the final analysis presented good quality data, reporting most of criteria suggested by Mischak et al. (Table 4). However, some reporting criteria missed in a significant number of included articles. As in the previous systematic review, the most unfulfilled criteria were the last three (validation, limitation acknowledgement and clear specification of author contribution to the manuscript). 
Z̃

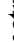

竞

क

ह

e्e

.0

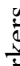

\%

$\stackrel{0}{\circ}$

竞

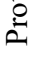

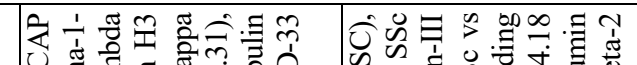

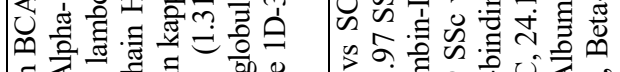
.

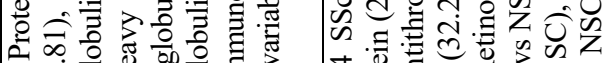

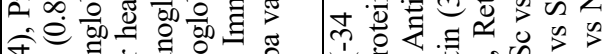

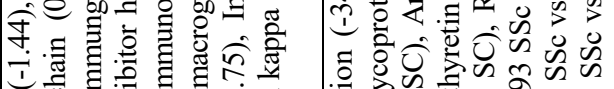

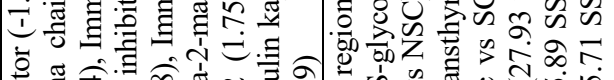

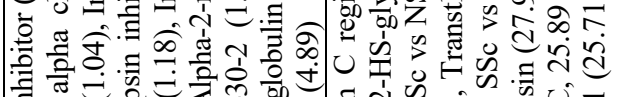
. ஆ 劳

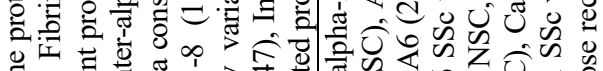
.

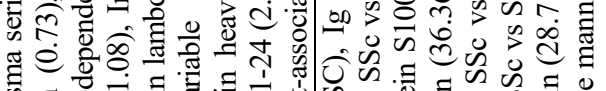

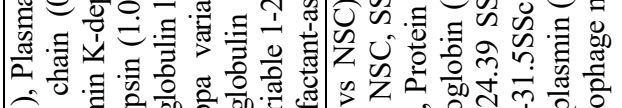

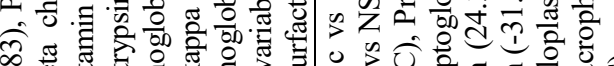

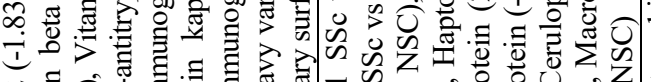
๗

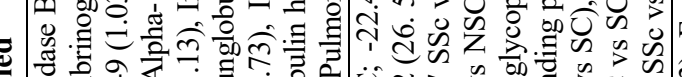

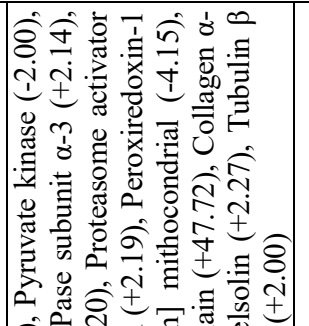

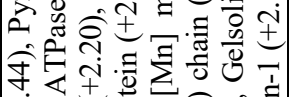
on

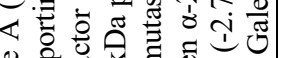

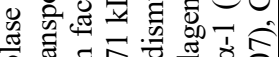

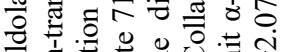
๘ 氜 矛

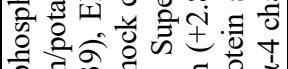

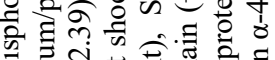

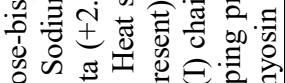
吉苍

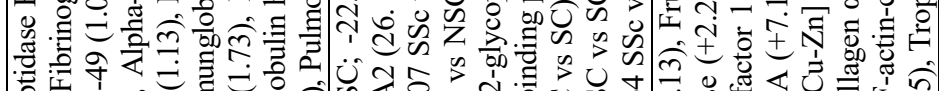

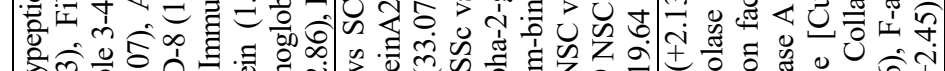

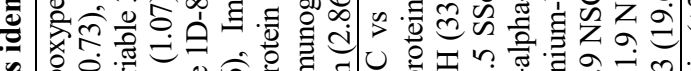
ó ש.

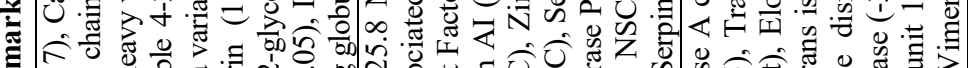
药

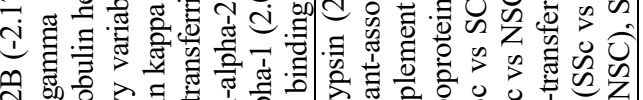
तิ

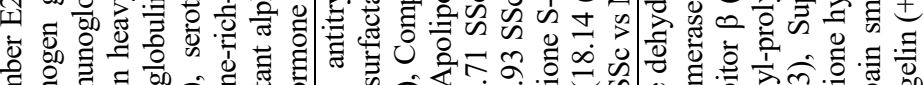

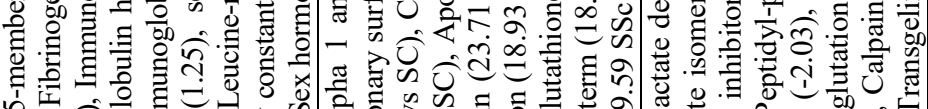

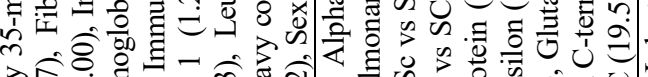

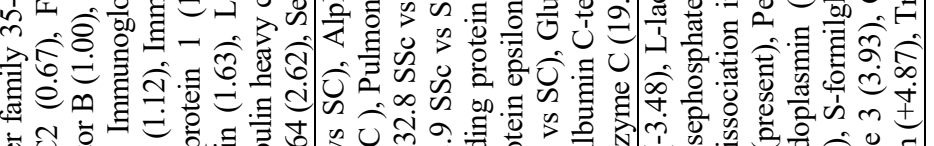

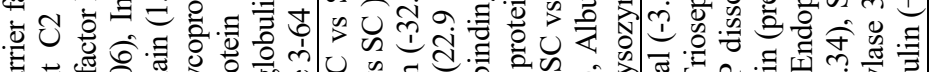

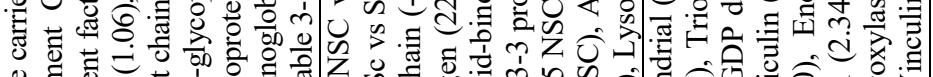
过

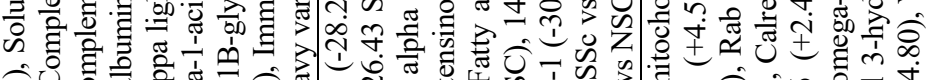

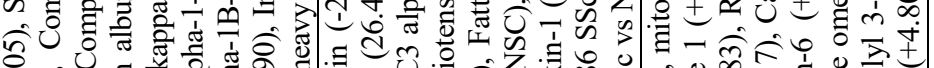

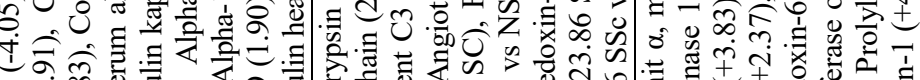
:

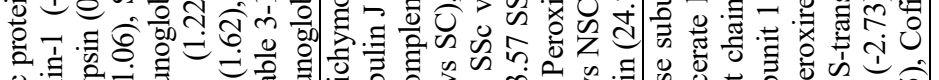

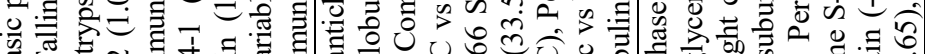
可

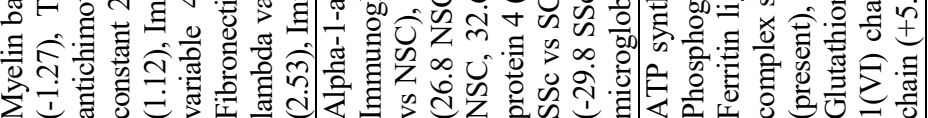

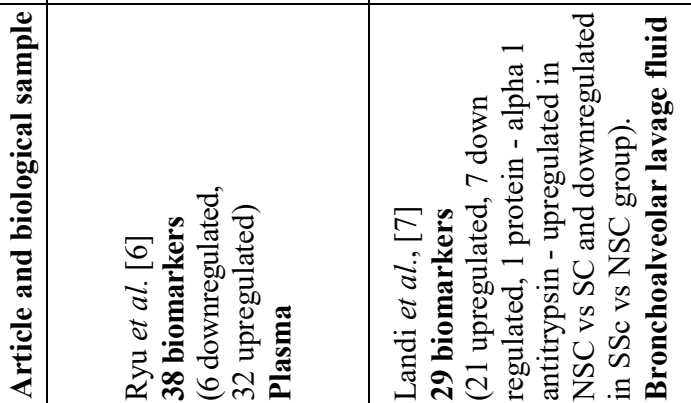

을 言的节

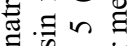

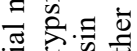

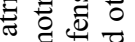
绕 $\infty$ E =

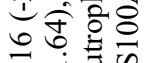
$\exists \rightarrow \bar{c}$ 产要

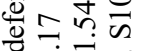
ij $=\hat{\sigma}$ एँ 更讨 空泀焉

至

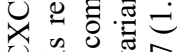

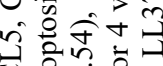

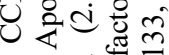
过宇宁 记过 जै +5 플 可 $+\frac{\bar{y}}{\mathrm{~g}} \mathrm{U}$ 형

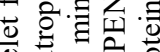
营 它氙

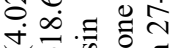
公记

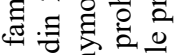

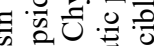

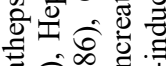
壱 के i 崩 Z蒙券 局:

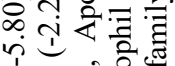
1

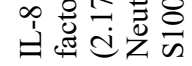

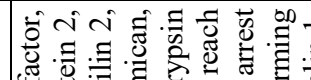

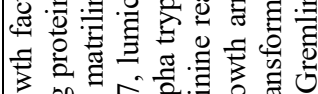

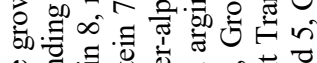

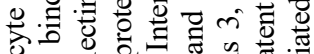

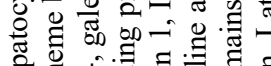
ํㅝㅇㅝ 过可 응.

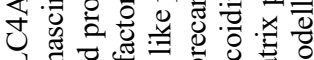

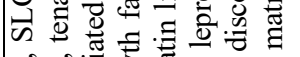

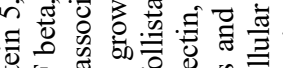

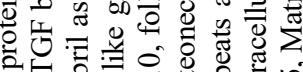

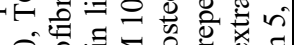

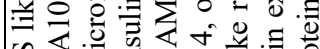

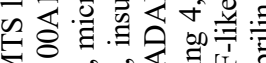

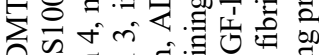

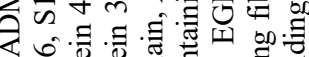
능 U.

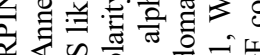
坣 क $\rightarrow$ 击 可安部

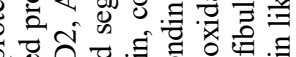

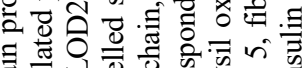
表

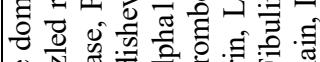

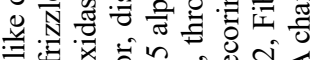

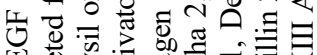

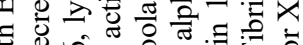
की

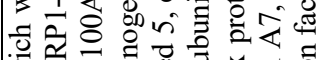

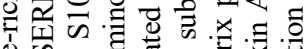

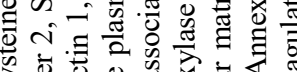

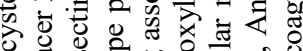
的 ฐ ब. 要 言罂

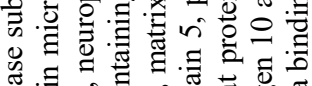

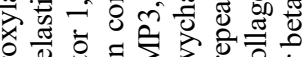
응 을 表要

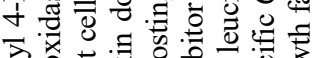

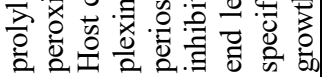
(1)

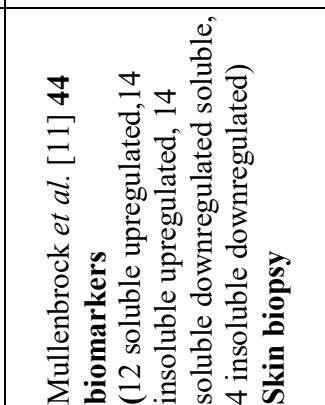




\begin{tabular}{|c|c|}
\hline & 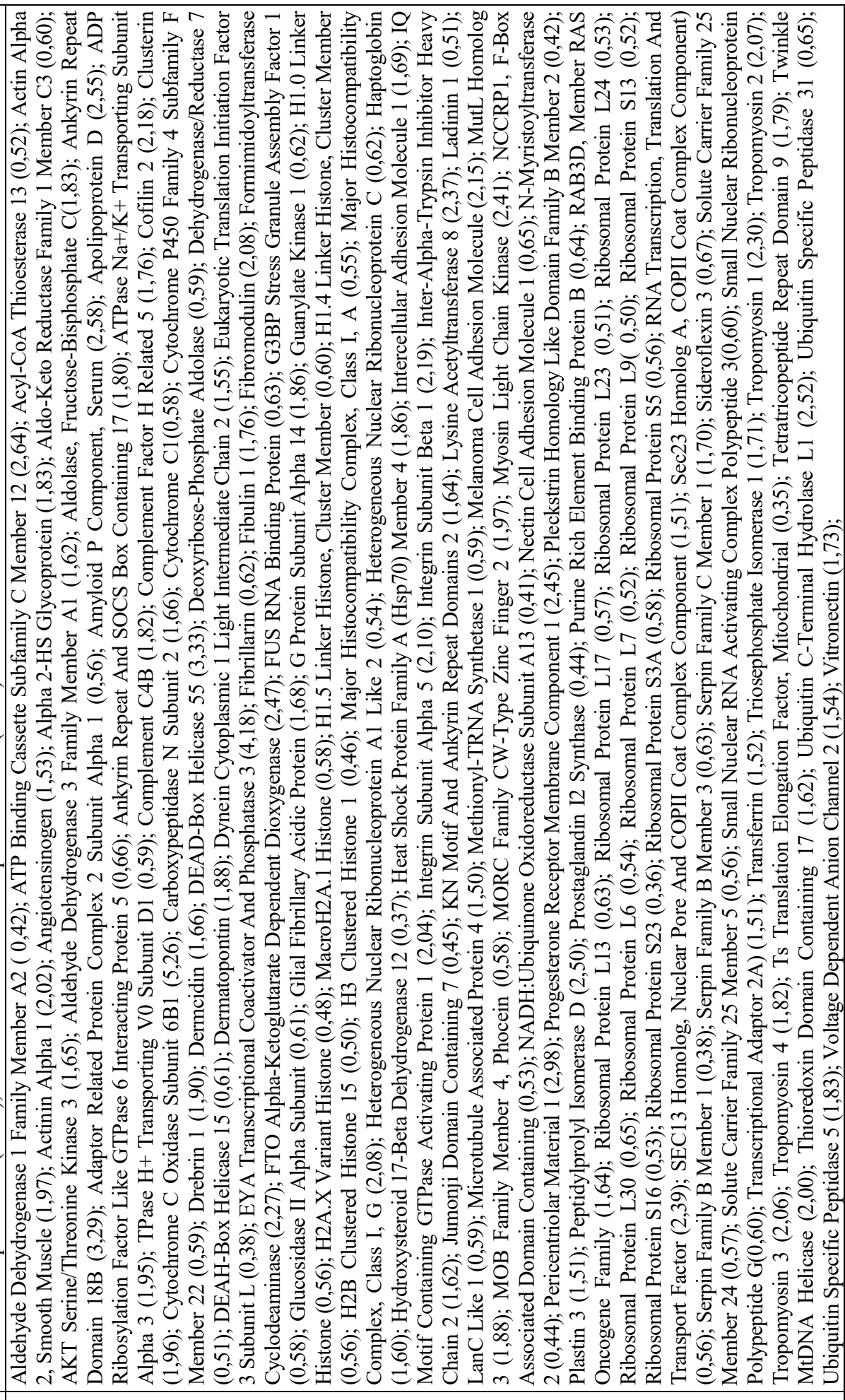 \\
\hline & 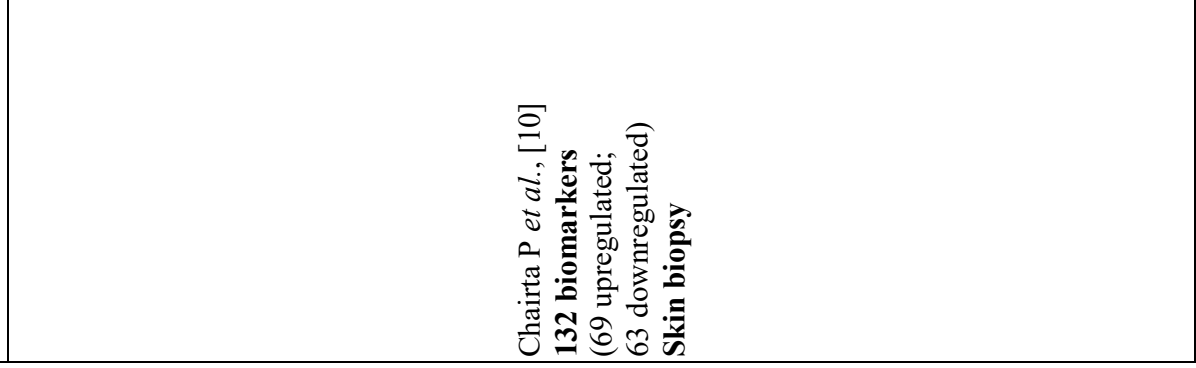 \\
\hline
\end{tabular}




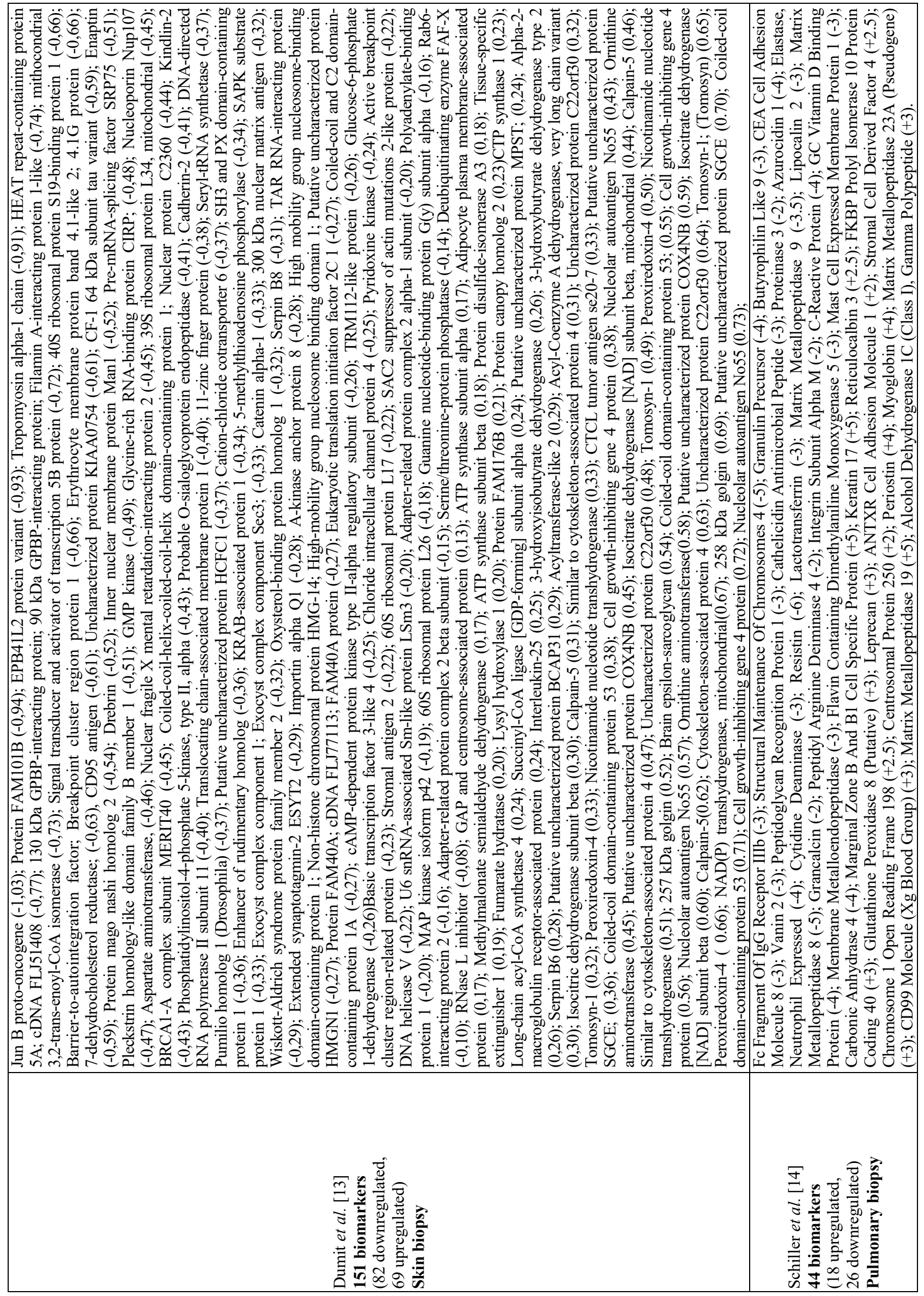


Table 4

Recommended aspects to be reported in clinical proteomics applied to articles included in the analysis. WB: Western Blot, IHC-Immunohistochemistry, ELISA-Enzyme Linked Immunosorbent Assay MRM: Multiple Reaction Monitoring

\begin{tabular}{|l|l|}
\hline \multicolumn{1}{|c|}{ Recommendation for reporting in scientific article } & \multicolumn{1}{c|}{ Included articles that fulfilled criteria } \\
\hline Identification and description of clinical question (9/9) & \multicolumn{1}{c|}{ All articles included in the analysis } \\
\hline Assessment of subject description (8/9) & $\begin{array}{l}\text { Ryu } \text { et al., [6] Landi } \text { et al., [7], van Bon } \text { et al., [9], Chairta } \text { et } \\
\text { al., [10], Mullenbrock } \text { et al., [11], Chaigne } \text { et al., [12], Dumi } \\
\text { et al. [13], Schiller } \text { et al., [14] }\end{array}$ \\
\hline Sampling description (9/9) & All articles included in the analysis \\
\hline Presentation of experimental methodology (9/9) & All articles included in the analysis \\
\hline Statistical approach (9/9) & All articles included in the analysis \\
\hline Validation of results (5/9) & $\begin{array}{l}\text { Landi } \text { et al., [7] (WB), Corallo } \text { et al., [8] (IHC), van Bon } \text { et } \\
\text { al., [9] (ELISA), Chairta } \text { et al., [10] (MRM), Schiller } \text { et al., } \\
\text { [14] (WB) }\end{array}$ \\
\hline Limitation acknowledgement (2/9) & Ryu et al., [6], Chaigne et al., [12] \\
\hline Clear presentation of each authors' contribution (5/9) & $\begin{array}{l}\text { Ryu } \text { et al., [6], Landi } \text { et al., [7], Chairta } \text { et al., [10], } \\
\text { Mullenbrock } \text { et al., [11], } \\
\text { Schiller } \text { et al., [14] }\end{array}$ \\
\hline
\end{tabular}

\section{Validation of identified candidate biomarkers}

Five articles out of 9 comprised validation of their findings. ELISA (Enzyme Linked Immunosorbent Assay), IHC (Immunohistochemistry), WB (Western Blot, 2 studies) and MRM (Multiple Reaction
Monitoring) were used for validation of some but not all identified candidate biomarkers. Only 13 biomarkers were validated (Table 5, S100A8/A9, UCHL1, PPID, DDX55, COX6B1, APCS, 14-33-epsilon, S100A6, collagen 1, vimentin, KRT 17, SDF4 and MZB1).

Table 5

Validation of biomarkers in included articles WB: Western Blot, IHC-Immunohistochemistry, ELISA-Enzyme Linked Immunosorbent Assay MRM: Multiple Reaction Monitoring

\begin{tabular}{|l|l|c|}
\hline \multicolumn{1}{|c|}{ Article } & \multicolumn{1}{c|}{ Validated biomarkers } & Validation technique \\
\hline van Bon et al., [9] & S100A8/A9 & ELISA \\
\hline Chairta et al., [10] & $\begin{array}{l}\text { UCHL1 (ubiquitin carboxy-terminal hydrolase L1), PPID (peptidylprolyl } \\
\text { isomerase D), DDX55 (Dead-Box Helicase 55), COX6B1 (Cythocrome } \\
\text { C oxidase 6B1) and APCS (Amyloid P) }\end{array}$ & MRM \\
\hline Landi et al., [7] & 14-3-3epsilon and S100A6 & WB \\
\hline Corralo et al., [8] & Collagen-1 and vimentin & IHC \\
\hline Schiller et al., [14] & $\begin{array}{l}\text { KRT17 (keratin 17) and SDF4 (45kDa calcium-binding protein) MZB1 } \\
\text { (Marginal Zone B And B1 Cell Specific Protein) }\end{array}$ & WB \\
\hline
\end{tabular}

\section{DISCUSSION}

This work is currently an update of a previous systematic review, aiming to summarize new biomarkers found in samples of Ssc patients to the already published data. This work focused on identifying biomarkers using mass spectrometry techniques and 2-dimensional electrophoresis. In the previous review, only 116 candidate biomarkers were identified, although many studies were included. In this review, another 539 candidate proteomic biomarkers are added, despite the fact that they were retrieved from a significantly smaller number of included articles. A possible explanation could be the fact that the current work included more articles that evaluated differential expression of biomarkers in biopsies (mostly cutaneous). When analyzing candidate biomarkers in tissue samples, the chances to find an increased number of candidate biomarkers using mass spectrometry proteomics is high due to the fact that the concentration of these proteins would be higher in tissue samples, compared to other biological sample [15].

It is obvious that biomarkers easily quantified in the clinical laboratory setting in any patient are those that are found in serum/plasma/urine (as minimally invasive procedures are needed in order to obtain sufficient biological sample for analysis). Plasmatic proteome is complex, and among proteins that are normally found in abundance, there are also present so called "tissue leakage products", and also proteins that are aberrantly secreted by diseased 
tissues (like tumors) [16]. As such, in addition to "in situ" validation and confirmation of a candidate biomarker, one could also be interested in its plasmatic profile (whether the protein is aberrantly present in circulation).

Therefore, studies that also analyze the distribution of candidate tissue biomarkers in the circulation are warranted. It is however expected that proteins that are secreted from the active site of inflammation/fibrosis to have low/very low abundance in plasma, and such characteristic would not make the biomarker easily detected using massspectrometry techniques. One could conclude that at least a part of the candidate biomarkers found from cutaneous and pulmonary specimens are candidate to be evaluated in plasma/serum of patients.

Interestingly, in this current update a higher number of candidate proteomic biomarkers were identified in plasma, compared to previous published data. There is a large majority of immunoglobulin chains that are candidate biomarkers, not a surprise having in mind the fact that Ssc is an autoimmune disease, and it is characterized by various autoantibodies. However, as they seem to be not specific, it is doubtful that they could be used for the prognosis and diagnosis of these patients. Specific autoantibodies carry higher predictive and prognostic values for the Ssc diagnosis and therapeutic response [17]. Compared to previous published data, some cytokines and chemokines also seem of interest for Ssc, being identified as candidate proteomic biomarkers using mass-spectrometry techniques. CXCL-2 and CXCL-7 seem promising candidate biomarkers, although CXCL-7 was found to be downregulated compared to controls. CXCL-7 is a platelet-derived chemokine, freed in the injury site, where it also transforms in its active form. This chemokine plays an important role in neutrophil recruitment, and neutrophil-platelet crosstalk [18]. Platelet derived chemokines have gained increased interest recently, as another chemokine CXCL-4 was associated with lung fibrosis and pulmonary arterial hypertension in Ssc patients [19]. Another interesting class of biomarkers identified is represented by defensins. Many defensins (human neutrophil peptides) were found to be candidate biomarkers for Ssc patients and independent validation studies have not yet been performed. It is possible there would be a connection between platelet chemokines (attracting and activating neutrophils in the active site of inflammation) and defensins. The exact role of this possible association alongside with implications for prognosis of Ssc patients should be further explored.

As presented before, a large number of candidate biomarkers emerged from cutaneous biopsies. These include molecules involved in fibrogenesis - both intracellular and extracellular proteins (collagen subunits, various remodeling enzymes, extracellular matrix proteins, cytoskeleton molecules), all suggesting the high degree of extracellular matrix remodeling in cutaneous lesions of Ssc patients. These molecules could be "leaking" from the tissue damage site into circulation. As such, some of them could also be evaluated in the circulation of Ssc patients, as a hallmark of active remodeling, with implications upon patient's prognosis and therapeutic responses. In addition to the biomarkers expressing inflammatory responses, another promising group of biomarkers are represented by molecules that are associated with oxidative stress. Enzymes like peroxiredoxin, glutathione peroxidase, glutathione reductase were found in multiple reports as potential biomarkers for Ssc. However, evaluation of circulatory levels of these enzymes could be difficult and it should be easier to identify their end-products, as it has been already proved that there is abnormal expression of these molecules [20]. An important aspect is the fact that markers of oxidative stress were found to be upregulated in many other pathologies, not only autoimmune, but also in various cancers or in elders [21, 22]. In addition, there are numerous reports in which oxidative stress molecules appear to have wide day to day fluctuations [23]. As such, evaluating enzymes that are upstream in the metabolic chain could be more useful, or at least as useful as evaluation of the endproducts. Studies that tackle this approach should be performed in Ssc patients.

Only one study evaluated proteomic biomarkers from BALF [7]. There were only few additional candidate proteomic biomarkers identified, compared to the previous systematic review. Among these, protein 14-3-3-epsilon and S100A6 were validated. Protein 14-3-3-epsilon comes from a larger family of chaperons - 14-3-3 proteins. They are conserved proteins in all eukaryotic cells, and play chaperon role in protein correct folding. 14-3-3 proteins are considered to be at the crossroad between aging and cancer as they have shown consistent expression patterns in these two conditions [24]. Therefore, care should be taken when analyzing 14-3-3 epsilon as proteomic biomarker in Ssc patients, and adjustments for patient's age should be taken under 
consideration. However, studies are still needed in order to validate most of candidate proteomic BALF biomarkers.

Although there was a relatively high number of identified biomarkers, only 13 were also validated in the selected studies (Table 5). Most biomarkers were validated from biopsy samples, while only one in plasma samples, and two from BALF. Among them, keratin 17 is of interest. It could be a valuable biomarker, due to the fact that it has virtually no expression in normal skin, but it is induced under various stress conditions (like inflammation). Also, keratin 17 proved to play various functions, like regulating immune response in cancer development and psoriasis [25].

In conclusion, although many candidate biomarkers were additionally identified, independent validation studies are needed in order to evaluate the importance of these biomarkers. Many of them could just be mirroring acute inflammation, autoimmune response and fibrosis, and they might have low specificity. However, some of them could not be good diagnostic biomarkers, but prognostic biomarkers (as it was the case of reticulocalbin (RCN) 1 and 3 validation study, which found similar expression in Ssc patients and healthy controls, but in the end a subgroup of patients with high RCN1 and 3 levels shared a common pattern of Ssc clinical characteristics [26]). This aspect should also be taken into account when performing validation studies. Trying to establish a threshold value in the healthy population is also very important, as few studies focused on the distribution of these candidate biomarkers in healthy population. The quest for promising biomarkers for Ssc patients is far from its ending, but alongside with development of high-throughput screening methods, the scientific community is getting close to achieving this goal.

Introducere. Sclerodermia este o boală autoimună caracterizată prin fibroză cutanată și tisulară ce asociază modificări vasculare. Scopul acestei sinteze sistematice a fost de a aduce la zi lista de biomarkeri proteomici candidat indentificați prin tehnici de spectrometrie de masă din probele biologice ale pacienților cu sclerodermie.

Metode. Bazele de date Medline și Scopus au fost evaluate pe 1 septembrie 2020. Au fost identificate articolele relevante din perioada martie 2014-septembrie 2020. Doi evaluatori independenți au evaluat rezultatele obținute.

Rezultate. Au fost identificate 97 de articole din care au rămas doar 9 pentru analiză. Au fost identificați 539 de biomarkeri proteomici candidat dintr-o varietate de produse patologice (un număr mult mai ridicat de biomarkeri comparativ cu studiul anterior). Cei mai mulți biomarkeri au fost identificați din probe bioptice cutanate. Numai 5 articole au inclus și o etapă de validare având un număr de 13 biomarkeri validati.

Concluzii. Deși au fost identificați biomarkeri, studii independente de validare sunt necesare pentru a evalua importanța acestora la pacienții cu sclerodermie.

Correspondence to: Paul Balanescu, M.D, Ph.D, University of Medicine and Pharmacy Carol Davila, Internal Medicine Chair, Colentina Clinical Hospital, 19-21 Stefan cel Mare street, Bucharest, Romania.

Tel: +40734584540

E-mail:plbalanescu@gmail.com

Conflict of interest disclosure: The authors declare no conflict of interest.

Acknowledgments: This work was supported by a grant of the Romanian Ministry of Education and Research, CNCS-UEFISCDI, project number PN-III-P1-1.1-PD-2019-0118, within PNCDI III.

\section{REFERENCES}

1. BHATTACHARYYA S, WEI J, TOURTELLOTTE WG, HINCHCLIFF M, GOTTARDI CG, VARGA J. Fibrosis in systemic sclerosis: common and unique pathobiology. Fibrogenesis Tissue Repair. 2012; 5(Suppl 1):S18.

2. MAYEUX R. Biomarkers: potential uses and limitations. NeuroRx. 2004; 1(2):182-8. 
3. FRANTZI M, BHAT A, LATOSINSKA A. Clinical proteomic biomarkers: relevant issues on study design \& technical considerations in biomarker development. Clin Transl Med. 2014; 3(1):7.

4. BĂLĂNESCU P, LĂDARU A, BĂLĂNESCU E, BĂICUȘ C, DAN GA. Systemic sclerosis biomarkers discovered using massspectrometry-based proteomics: a systematic review. Biomarkers. 2014; 19(5):345-55.

5. MISCHAK H, ALLMAIER G, APWEILER R, ATTWOOD T, BAUMANN M, BENIGNI A, et al. Recommendations for biomarker identification and qualification in clinical proteomics. Sci Transl Med. 2010; 2(46):46ps42.

6. RYU C, WALIA A, ORTIZ V, PERRY C, WOO S, REEVES BC, et al. Bioactive Plasma Mitochondrial DNA is Associated With Disease Progression in Scleroderma-Associated Interstitial Lung Disease. Arthritis Rheumatol. 2020 Jun 30. doi: 10.1002/art. 41418. Epub ahead of print.

7. LANDI C, BARGAGLI E, CARLEO A, REFINI RM, BENNETT D, BIANCHI L, et al. Bronchoalveolar lavage proteomic analysis in pulmonary fibrosis associated with systemic sclerosis: S100A6 and 14-3-3e as potential biomarkers. Rheumatology (Oxford). 2019; 58(1):165-178.

8. CORALlO C, SANTUCCI A, BERNARDINI G, FIGURA N, LEONCINI R, RIOLO G, et al. Proteomic Investigation of Dermal Fibroblasts Isolated from Affected and Unaffected Skin Samples from Patients with Limited Cutaneous Systemic Sclerosis: 2 Distinct Entities? J Rheumatol. 2017; 44(1):40-48.

9. VAN BON L, COSSU M, LOOF A, GOHAR F, WITTKOWSKI H, VONK M, et al. Proteomic analysis of plasma identifies the Toll-like receptor agonists S100A8/A9 as a novel possible marker for systemic sclerosis phenotype. Ann Rheum Dis. 2014; 73(8):1585-9.

10. CHAIRTA P, NiCOLAOU P, SOKRATOUS K, GALANT C, HOUSSIAU F, OULAS A, et al. Comparative analysis of affected and unaffected areas of systemic sclerosis skin biopsies by high-throughput proteomic approaches. Arthritis Res Ther. 2020; 22(1):107.

11. MULLENBROCK S, LIU F, SZAK S, HRONOWSKI X, GAO B, JUHASZ P, et al. Systems Analysis of Transcriptomic and Proteomic Profiles Identifies Novel Regulation of Fibrotic Programs by miRNAs in Pulmonary Fibrosis Fibroblasts. Genes (Basel). 2018; 9(12):588.

12. CHAigne B, CLARY G, LE GALl M, DUMOITIER N, FERNANDEZ C, LOFEK S, et al. Proteomic Analysis of Human Scleroderma Fibroblasts Response to Transforming Growth Factor- $\beta$. Proteomics Clin Appl. 2019; 13(4):e1800069.

13. DUMIT VI, KÜTTNER V, KÄPPLER J, PIERA-VELAZQUEZ S, JIMENEZ SA, BRUCKNER-TUDERMAN L, et al. Altered MCM protein levels and autophagic flux in aged and systemic sclerosis dermal fibroblasts. J Invest Dermatol. 2014; 134(9):2321-2330.

14. SCHILLER HB, MAYR CH, LEUSCHNER G, STRUNZ M, STAAB-WEIJNITZ C, PREISENDÖRFER S, et al. Deep Proteome Profiling Reveals Common Prevalence of MZB1-Positive Plasma B Cells in Human Lung and Skin Fibrosis. Am J Respir Crit Care Med. 2017; 196(10):1298-1310.

15. SCHIESS R, WOLLSCHEID B, AEBERSOLD R. Targeted proteomic strategy for clinical biomarker discovery. Mol Oncol. 2009; 3(1):33-44.

16. ANDERSON NL, ANDERSON NG. The human plasma proteome: history, character, and diagnostic prospects. Mol Cell Proteomics. 2002; 1(11):845-67.

17. KAYSER C, FRITZLER MJ. Autoantibodies in systemic sclerosis: unanswered questions. Front Immunol. $2015 ; 6: 167$.

18. BROWN AJ, SEPURU KM, SAWANT KV, RAJARATHNAM K. Platelet-Derived Chemokine CXCL7 Dimer Preferentially Exists in the Glycosaminoglycan-Bound Form: Implications for Neutrophil-Platelet Crosstalk. Front Immunol. 2017; 8:1248.

19. VAN BON L, AFFANDI AJ, BROEN J, CHRISTMANN RB, MARIJNISSEN RJ, STAWSKI L, FARINA GA, et al. Proteome-wide analysis and CXCL4 as a biomarker in systemic sclerosis. N Engl J Med. 2014 Jan 30; 370(5):433-43.

20. LUO JY, LIU X, JIANG M, ZHAO HP, ZHAO JJ. Oxidative stress markers in blood in systemic sclerosis: A meta-analysis. Mod Rheumatol. 2017; 27(2):306-314.

21. LEPARA Z, LEPARA O, FAJKIĆ A, REBIĆ D, ALIĆ J, SPAHOVIĆ H. Serum malondialdehyde (MDA) level as a potential biomarker of cancer progression for patients with bladder cancer. Rom J Intern Med. 2020; 58(3):146-152.

22. KUDRYAVTSEVA AV, KRASNOV GS, DMITRIEV AA, ALEKSEEV BY, KARDYMON OL, SADRITDINOVA AF, et al. Mitochondrial dysfunction and oxidative stress in aging and cancer. Oncotarget. 2016 Jul 19; 7(29):44879-44905.

23. GOLDFARB AH, GARTEN RS, WALLER J, LABBAN JD. Day to Day Variability and Reliability of Blood Oxidative Stress Markers within a Four-Week Period in Healthy Young Men. J Biomark. 2014; 2014:248313.

24. FAN X, CUI L, ZENG Y, SONG W, GAUR U, YANG M. 14-3-3 Proteins Are on the Crossroads of Cancer, Aging, and AgeRelated Neurodegenerative Disease. Int J Mol Sci. 2019; 20(14):3518.

25. YANG L, ZHANG S, WANG G. Keratin 17 in disease pathogenesis: from cancer to dermatoses. J Pathol. 2019; $247(2): 158-165$.

26. BALANESCU P, LADARU A, BALANESCU E, POMPILIAN V, GOLOGANU D, CARAIOLA S, et al. Circulating Reticulocalbin 1 and Reticulocalbin 3 in Systemic Sclerosis Patients: Results of a Case Control Study. Clin Lab. 2016; 62(6):1109-16.

Received $28^{\text {th }}$ October 2020 